\title{
EDUCANDO E CUIDANDO PARA OS DESAFIOS DA VIDA: COEXISTÊNCIA PEDAGÓGICA ENTRE NATUREZA, CULTURA E CRIATIVIDADE
}

\author{
Elani Cristina Vieira Magalhães de Castro $^{1}$ \\ José Dácio Gomes de Castro Neto ${ }^{2}$
}

\begin{abstract}
Resumo: $\mathrm{O}$ artigo tem como objetivo demonstrar as práticas educativas do Colégio Eureca em São Luís - MA que contribuem com formação de cidadãos independentes, criativos e responsáveis consigo mesmo, com as outras pessoas e com o meio ambiente. Descreve algumas experiências transdisciplinares desenvolvidas. Aborda aspectos criativos contidos nas atividades educativas realizadas, sempre considerando o desafio de construir práticas pedagógicas que articulem o homem, a natureza e a cultura de forma criativa. Ressalta-se também a importância do protagonismo das crianças na construçáo das suas aprendizagens, assim como a necessidade da formaçáo docente que atenda o desafio de uma educação transformadora.
\end{abstract}

Palavras-chave: Transdisciplinaridade; Natureza; Cultura; Práticas educativas.

\section{EDUCATING AND CARING FOR THE CHALLENGES OF LIFE: PEDAGOGICAL COEXISTENCE BETWEEN NATURE, CULTURE AND CREATIVITY}

\begin{abstract}
The article aims to demonstrate the educational practices of the Eureka College in. Which contribute to the formation of independent, creative and responsible citizens with themselves, with others and with the environment. It describes some transdisciplinary experiences developed. It addresses creative aspects contained in educational activities, always considering the challenge of constructing pedagogical practices that articulate man, nature and culture in a creative way. It is also important to emphasize the role of children in the construction of their learning, as well as the need for teacher training that meets the challenge of a transformative education.
\end{abstract}

Keywords: Transdisciplinarity; Nature; Culture; Educational practices.

1 Pedagoga. Mestre em Educação. Colégio Eureca. São Luís - MA - Brasil. elanidecastro@colegioeureca.com.br

2 Administrador. Mestrando em Meio Ambiente. Universidade Ceuma. São Luís - MA. daciodecastro@gmail.com 


\section{INTRODUÇÃO}

Observa-se a necessidade do homem se compreender como parte de uma natureza complexa, que a sua capacidade cognitiva deve ser melhor articulada para desenvolvimento de práticas biossustentáveis, por uma questão ética e de sobrevivência.

O ambiente escolar tem demonstrado ser um cenário fértil para o desenvolvimento de práticas educativas, pautadas na pedagogia ecossistêmica e a transdisciplinaridade, que possibilitam a aproximação dos alunos a natureza, quebra-se o paradigma de homem dominador, o que abre espaço para o homem relacional.

Diante do exposto, este artigo tem como objetivo demonstrar as práticas educativas do Colégio Eureca que contribuem com formação de cidadãos independentes, criativos e responsáveis consigo mesmo, com as outras pessoas e com o meio ambiente. Será dividido em duas seções, onde a primeira versará sobre o Colégio Eureca, natureza e cultura; e a segunda seção serão demonstrados as práticas educativas e os resultados que geram para a comunidade, os alunos e os seus familiares.

\section{O COLÉGIO EURECA, NATUREZA E CULTURA}

O Colégio Eureca iniciou as suas atividades educativas em dezembro do ano de 2009, em São Luís - MA, inicialmente seu trabalho destinava-se a prestar serviços educacionais para crianças de 6 meses a 5 anos de idade, caracterizava-se como uma escola pequena, com um currículo tradicional, embora investisse em ações de preservação do meio ambiente e culturais. No ano de 2011, a escola firmou parceria com a Escola Villa passa a trabalhar com a pedagogia ecossistêmica. Em 2017 escola atende crianças da educação infantil e ensino fundamental até o $4^{\circ}$ ano.

Utiliza do significado da expressão "eureca" que significa "achei”, "descobri”" para fundar a sua prática de aprender e ensinar, a cada projeto concluído se descobre nas práticas, novos olhares para conduzir os fazeres. Utilizando-se do lema: educando e cuidando para os desafios da vida, o que lhe permite educar as crianças para transitar por caminhos de incertezas, porém seguros pela consciência que constroem sobre o mundo, sendo esse natural (natureza) ou forjados por eles próprios (meio ambiente).

O Colégio assume o importante papel de permitir que os seus alunos não compreendam a natureza "[...] como um inimigo a ser combatido e subjugado, [...]" abstração que nascem das nossas concepções econômicas e científicas (DREW, 2014, p. 2), mas sim, pensar nele como uma totalidade complexa e que o homem é parte integrante, no entanto, diferenciado dos outros seres pela cultura construída pelo meio em que vivem (MORIN, 1988).

Desta forma, o homem toma consciência da sua importância, espera-se, como parte de um todo cheio de conexões, e que condicionar a natureza apenas 
às suas necessidades pode resultar na extinção da sua espécie, como exposto por Dulley (2004, p.21):

Considera-se que a natureza não é estática, e sim dinâmica, está sempre se transformando de modo imperceptível e/ou violento, mas nela sempre atuam mecanismos próprios ou naturais que buscam restaurar o equilíbrio. Os sistemas sociais produtivos humanos, quer trabalhem no sentido favorável, quer desfavorável ao ambiente e natureza, não têm capacidade de destrui-lo(a). Podem sim, tornar o seu meio ambiente ${ }^{3}$ impróprio para a sobrevivência da espécie humana, de tal modo que a espécie seja eventualmente excluída da natureza com a deterioração e extinção do seu meio ambiente.

Reconhece-se que para a quebra dessa visão de homem dominador da natureza para partícipe, fez-se necessário adotar a pedagogia ecossistêmica que Limaverde (2015) ilustra como uma "teia curricular" dotada de mapas para demonstrar as relações do homem consigo mesmo, com o meio social e com o meio ambiente.

Essa organização curricular permite organizar vivências utilizando os conteúdos das disciplinas a partir da abordagem transdisciplinar, sempre contextualizando os conteúdos à vida real, propondo situações problemas, confrontando a produção de conhecimento a resolução de problemáticas socioambientais, a partir de uma dinâmica curricular em que o aluno é protagonista do conhecimento produzido.

Assim, Suanno e Freitas (2016, p. 87) justificam essa prática, quando falam da finalidade da escola para aumento da compreensão sobre as questões mais amplas da sociedade:

[...] a escola tem por finalidade possibilitar condições de aprendizagem que considerem as categorias contexto, contexto global, multidimensional e complexo, pois, dessa maneira, o conhecimento torna-se pertinente para o aluno, criando condições para a compreensão das questões mais amplas da sociedade e uma possível intervenção para a prevenção e solução de problemas, exercendo, assim, uma cidadania crítica. Para que isso seja possível, a escola deve valorizar práticas inter e transdisciplinares que favoreçam a construção colaborativa do conhecimento.

A prática pedagógica do Colégio Eureca é marcada por dois aspectos fundantes: os estudos ambientais que se desdobram em práticas coletivas que se estendem para fora dos muros da escola, mobiliza outras pessoas a aderirem às práticas biossustentáveis, e o outro, pela necessária "utilização" da cultura local e brasileira como fonte inspiradora para as aulas de teatro e música. Insere e valoriza a cultura como conteúdo para a construção de identidade e sentimento de pertencimento de nossos alunos ao local em que vivem.

3 A noção de ambiente pode ser considerada como resultado do pensamento e conhecimento humano e do seu trabalho intelectual e físico sobre a natureza, e corresp0onde, portanto, à natureza trabalhada (DULLEY, 2004, p. 22). 
Assim, a natureza e a cultura, ao mesmo tempo que compõe um cenário de da pedagogia, torna constante, o "vir a aprender", "vir a cuidar" vir a fazer" e "vir a ser". Portanto a construção do humano passa por uma consciência de si, da natureza e das relações estabelecidas nos processos comunicativos, culturais e educativos pertencentes a espécie humana.

Torre, Pujol e Moraes (2013, p. 74-75) incrementa quando fala da importância do respeito as diferenças culturais para construção de um mundo mais humano, no sentido positivo da palavra.

[...] a cidadania planetária como identidade do pensamento humanista, com relação ao respeito às diferenças culturais e de outros tipos. A diversidade é riqueza. Uma educação moderna deve formar pessoas autônomas, independentes, críticas e criativas, capazes de construir seu projeto de vida, de participar na comunidade e buscar a felicidade onde consideram apropriado.

Compartilhando do pensamento de que diversidade é riqueza, pode-se dizer que as atividades desenvolvidas dentro e fora do Colégio que privilegiam as diferenças culturais são percebidas como diferenciais, e que contribuem para de cidadãos participativos da vida comunitária, no entanto tem exigido dos professores posturas diferentes das que normalmente estão acostumados a ter, pois esse cenário escolar requer desse profissional dinamismo e abertura para troca de informações.

Diante da facilidade que os alunos têm de manusear informações, exige-se dos professores novas práticas, pois jovens alunos não respondem positivamente aos processos tradicionais de integração, aprendizagem e síntese. Fala-se de jovens com cérebros programados que não percebem da mesma maneira, se comunicam e aprendem da mesma forma (SUANNO; PUIGGRÒS, 2012)

Na prática do professor, encontram-se subjacentes modelos de educação e de escola fundamentados em determinadas teorias do conhecimento e da aprendizagem. Ao mesmo tempo em que a educação é influenciada pelo paradigma da ciência, aquela também o determina. O modelo da ciência que explica a nossa relação com a natureza e com a própria vida, esclarece também a maneira como apreendemos e compreendemos o mundo, mostrando que o indivíduo ensina e constrói o conhecimento a partir de como ele compreende a realização desses processos. (MORAES, 1997, p. 3)

Há necessidade de reinvenção das práticas escolares, investir em formação de professores a partir de um novo modelo educacional, que tenha como foco na constituição de indivíduos que possam interagir com as condições diversas da vida, de maneira ética (SUANNO; FREITAS, 2016)

A prática pedagógica numa abordagem transdisciplinar, faz com que uma série de organizações se projetem no sentido de fazer valer todo o potencial das pessoas como protagonistas de suas vidas e de seus processos de aprendizagens individual e coletiva, então, o que faz sentido nesse processo de crescimento individual e coletivo? Que estratégias de ensino favorecem a aprendizagem dos alunos? O que mobiliza os educadores a utilizarem de estratégias diferenciadas? 
Como os pais percebem a aprendizagem dos filhos? Qual a prática de trabalho do Colégio Eureca?

\section{O COLÉGIO EURECA E SUA PRÁTICA}

Descreve-se a seguir algumas atividades que já fazem parte do calendário anual, tais quais: Quermesse, Arraial Matracando no Eureca, Blitz Ecológica e Coral Uirapuru.

A Quermesse é realizada no mês de maio, neste mês a cidade de São Luís "respira" o clima das manifestações folclóricas que antecede os arraiais. A referida atividade aconteceu na Casa do Maranhão, um museu situado no Centro Histórico de São Luís. A atividade traz o novo quando convidam os alunos para ir ao museu, não na condição de visitante, mas de executores da programação, num processo que privilegia a integração entre os educadores do colégio, alunos, familiares e equipe de funcionários do museu.

Entre as atividades da programação, destacam-se: acerte o rabo do bumba meu boi, acerte o alvo, pescaria, oficina de tambor de crioula (dança afro-brasileira), contação da lenda de Catirina e Pai Francisco (lenda do bumba boi), o lançamento da revista em quadrinhos Pai Francisco e Catirina e ainda, um delicioso piquenique de comidas típicas.

A Quermesse se destaca, também, pela ocupação desse espaço de história e cultura do maranhão, aproxima os conteúdos trabalhados no ambiente escolar, dando mais vida e significado a esses, aproxima também os adultos a cultura local, despertando para a valorização dos saberes, costumes, música e culinária e da sua gente. Assim sendo, contribui com a construção de um novo olhar sobre a natureza "[...] a natureza em si, não passa de uma abstração. Não encontramos senão uma ideia de natureza que toma sentido diferente segundo as épocas e os homens." (LENOBLE, 1969 apud DULLEY, 2004, p. 16)

Apresentar novos cenários onde os próprios alunos ajudaram a construir tornou o processo mais envolvente, estimulou a construção de muitas brincadeiras de sucatas, dando um significado maior a cada detalhe da atividade, se apropriaram das toadas de bumba meu boi e do tambor de crioula. O envolvimento das famílias só reforça o reconhecimento da importância de se estabelecer a comunicação entre cultura, novas gerações e escola.

Desta forma, o professor assume um importante papel, pois "precisa envolver o aluno no processo de aprendizagem dando oportunidade ao aluno na construção do conhecimento, lhe dando autonomia para que ele dê sugestões, [...] possibilitando que ele participe construindo a sua própria aprendizagem". (SUANNO; FREITAS, 2016, p. 115)

Portanto, os espaços de aprendizagem precisam ser configurados e reconfigurados, tornar dinâmica a produção do conhecimento a partir da cultura, estabelecer diálogos com culturas diferentes da sua. A escola apresenta uma fecunda arena de subjetivação necessária a diferentes culturas. 
No entanto, o modelo prevalecente que prega o modo linear de ensinar, dificulta a sensibilização do homem para o seu papel social, como dito por $\mathrm{La}$ Torre, Pujol e Moraes (2013, p. 131):

O padrão educacional vigente está condicionado pelo pensamento linear e determinista o que considera o pensamento e o erro como uma expressão de ignorância e incompetência. [...] nesse padrão educacional, prevalece o uso de lógicas que desassociam o pensamento do corpo, que negam a espiritualidade e o diálogo com o corpo, que disciplinam nossos corpos, pensamentos, emoções, sentimentos e crenças.

A prática do Colégio Eureca, ao contrário do modelo educacional vigente, busca constituir a escola como um espaço para aprender e ensinar a sensibilidade, pertinente ao seu papel formador, entretanto não tem sido tarefa fácil, inúmeras influências são impostas pelo modelo tradicional de educação, pela indústria cultural, por uma sociedade imediatista, pelo uso das tecnologias sem orientação adequada e da própria confusão quanto ao papel formador da escola.

A criatividade pode ser tratada, nesse contexto, como um importante instrumento para a mitigação das barreiras ao novo paradigma educacional, conceitua-se como, "a capacidade humana para gerar ideias ou conexões imaginativas em um determinado campo, com um certo nível de originalidade e de aportação de valor (SUANNO; PUIGGRÒS, 2012, p.108)".

Pode ser definida também, "como um fenômeno multidimensional envolvendo aspectos cognitivos, afetivos, sociais e culturais. Assim sendo, estes aspectos se interagem das mais diferentes maneiras, gerando diversidade nos estilos de pensar e criar". (SUANNO; PUIGGRÒS, 2012, p. 347)

Desta forma, as ações desenvolvidas pelo Colégio Eureca, além de provocar o comportamento interativo do homem consigo, com o outro e com o meio ambiente, contribui para formação de novos estilos de pensar e agir, vistos nas práticas dos professores e na produção dos alunos.

O arraial Matracando no Eureca exalta a partir do teatro, música e dança; a importância da natureza como inspiradora de várias manifestações culturais, os costumes do homem da roça, dos escravos, as representações através da alto do bumba meu boi, dança do coco, quadrilha, dança do Cacuriá, onde os alunos conhecem os instrumentos e as indumentárias que compõe as manifestações culturais, o jeito de cantar toadas, a discussão acerca da trama da lenda e seus personagens, a construção boizinhos e bandeirolas de material reciclado juntamente com suas famílias.

O envolvimento das professoras, a escolha do repertório musical, coreografias, das roupas, da decoração, do cardápio, as estratégias pedagógicas utilizadas para desenvolver os conteúdos que envolvem uma atividade dessa magnitude requer um trabalho coletivo de reconhecimento da diversidade cultural, dos diálogos que carecem serem abertos dentro do contexto escolar e social sobre cada manifestação cultural sua existência, resistência e relevância social. 
Suanno e Puiggròs (2012, p.137) mencionam a importância da preparação dos professores para contenção da sobreposição da cultura socialmente oprimidas:

A necessidade da formação para o trato da diversidade traz à tona as expectativas, os interesses, os significados, as resistências; compreender as suas representantes para poder justificar suas atitudes e posturas no intuito de decodificar os mecanismos de discriminação e opressão que ocultam as vozes das culturas marginalizadas socialmente. E para concretizar uma formação integradora sobre a diversidade que relacione, interprete e compreenda o mundo interior e exterior (subjetivo, intersubjetivo, coletivo e sociocultural dos professores)

A realização da Blitz Ecológica está articulada a um conjunto de ações ambientais que são trabalhadas no decorrer do ano letivo, como estudo no mangue, praias, estudo sobre o uso indiscriminado de descartáveis, o cuidado com a fauna, onde os alunos cuidam diariamente dos animais da escola, preparam a alimentação das galinhas, jabutis e peixes, estudam o comportamento desses animais, suas características, nome cientifico e outros aspectos.

Nessa atividade é tratado do plantio e cuidado com a flora no espaço escolar; nas formas de plantas frutíferas, plantas medicinais, plantas de jardim. Surgem inúmeras atividades como: produzir adubo orgânico e distribuir nas plantas; processo de germinação e cultivo das diferentes plantas; estudo das propriedades nutricionais e medicinais dos vegetais; identificação de sabores, textura e cheiro; fabricação de chás e xaropes com ervas medicinais; degustação de chás com as famílias.

A culminância se deu através da mobilização social realizada na Avenida Litorânea, onde a comunidade escolar e outros apoiadores (Grupo de Escoteiros, Polícia Rodoviária Militar e Secretaria Estadual do Meio Ambiente) se reuniram para lutar por causas ambientais da cidade de São Luís, houve a distribuição de lixocar com panfletos produzidos pelos alunos, circuito ecológico e danças circulares.

O Coral Uirapuru é produto das atividades de música e teatro, composto por alunos de 7 a 10 anos de idade tem como repertório músicas ecológicas e da cultura maranhense, em suas apresentações tem revelado grande capacidade criativa, utiliza-se da linguagem poética e teatral, suas roupas são coloridas como a natureza, maquiagem cênica, são usados instrumentos musicais indígenas, como: apitos, chocalhos.

Esta experiência revelou inúmeras possibilidades, quanto ao desenvolvimento das linguagens musical e teatral, o que fortalece a valorização da cultura como conteúdo motivador para a prática educativa criativa.

Essas atividades práticas ativam a conexão das crianças e famílias com o planeta terra, através de experiências que estimulam o pensar e agir conectados a um contexto existencial que se movimenta e se reconhece na relação natureza, homem e cultura, vistos sob a ótica das diferentes áreas do conhecimento interligadas. 


\section{CONSIDERAÇÓES FINAIS}

O ambiente escolar é propício para conscientização do homem acerca do seu papel em um mundo complexo e cheio de incertezas, esse tem dado sinal que as antigas equações ou modelos matemáticos não são capazes de resolver ou evitar os problemas socioambientais contemporâneos.

Assim sendo, o modelo educacional tradicional fundado na construção disciplinar do conhecimento, que dado a linearidade das suas práticas não consegue enxergar a complexidade das relações no mundo pós-moderno, abre espaço para a educação transdisciplinar que prima pela formação integral do homem, considerando os seus aspectos cognitivos, sociais, emocionais e espirituais.

Diante dessa emergente necessidade, o Colégio Eureca, por meio da pedagogia ecossistêmica, oportuniza para os seus alunos novas formas de aprendizagens, colocando-os em contato com problemas socioambientais que a partir do conhecimento disciplinar, saberes populares, cultural e espirituais, propõem soluções criativas. Assim estabelece um movimento de aprendizagens contínuas entre educadores, alunos e familiares, fundados na natureza e cultura.

\section{REFERÊNCIAS}

DREW, David. Processos interativos homem - meio ambiente. 9. ed. Rio de Janeiro: Bertrand Brasil, 1997, 2014.

DULLEY, Richard Domingues. Noção de natureza, ambiente, meio ambiente, recursos ambientais e recursos naturais. Revista Agric., São Paulo,v. 51, n. 2, p. 15-26, jul./dez. 2004. Disponível em: < http://www.abes-df.org.br/upload/artigo/2014_05_27/ asp-2-04-2-20140527160132.pdf>. Acesso em: out. 2017.

LIMAVERDE, Patrícia. Pedagogia ecossistêmica: educação transdisciplinar na Escola. Fortaleza: Editora Vila, 2015.

MORAES, Antônio Carlos Robert. Meio ambiente e ciências humanas. 4. ed. São Paulo: Annablume, 2005.

MORAES, Maria Cândida. O Paradigma Educacional Emergente. Campinas/SP: Papirus, 1997.

MORIN, E. O paradigma perdido: a natureza humana. 4. ed. Portugal: Publicações Europa-América, 1988. 222 p.

SUANNO, Marilza Vanessa Rosa; FREITAS, Carla Conti de. (Org.). Razão sensível e complexidade na formação de professores: desafios transdisciplinares. Anápolis: UEG, 2016.

SUANNO, Marilza Vanessa Rosa; Puigròss, Núria Rajadell (Org.). Didática e formação de professores: perspectivas e inovações. Goiânia: CEPED, 2012. 
TORRE, Saturnino de La; PUJOL, Maria Antônia; MORAES, Maria Cândida (Coords.). Documentos para transformar a educação: um olhar complexo e transdisciplinar. Rio de Janeiro: Wak Editora, 2013. 